\title{
Stem Cell-Based Stroke Treatment
}

\author{
Firoozeh Alavian ${ }^{1}$, Sorayya Ghasemi ${ }^{2 *}$ \\ ${ }^{1}$ Department of Basic Sciences, Farhangian University, Tehran, Iran
}

${ }^{2}$ Cellular and Molecular Research Center, Basic Health Sciences Institute, Shahrekord University of Medical Sciences, Shahrekord, Iran

Article Info:

Received: 23 Apr 2019

Revised: 2 Sep 2019

Accepted: 24 Sep 2019

\section{A BSTRACT}

Introduction: Self-renewable and differentiable cells or stem cells are high-potential cells for the repair of tissue damages. Therefore, this is a promising approach to treat brain tissue damage following neurological disorders, such as stroke. Animal studies have shown the beneficial effects of various stem cells, including embryonic stem cells, inducible pluripotent stem cells, neural stem cells, and mesenchymal stem cells, in stroke recovery. The healing process may be due to replacement of damaged cells, neuroprotective effects, endogenous neurogenesis, angiogenesis, modulation of inflammation, and immune responses. Currently, stem cell-based methods have attracted the attention of many scientists and practitioners due to their curative effect on stroke. Conclusion: Although numerous clinical studies indicate that stem cells have high efficacy and safety in stroke treatment, some key issues should be considered. The positioning of these cells, survival, traceability, immunity, and cell transplantation protocols, such as the rate of usage and timing, are the challenges in stem cell-based treatment. Although the stem cell therapy is a potential new approach for treatment of stroke, further studies are still needed to improve the efficacy of this therapeutic method. This review article is a summary of current knowledge and concerns of the use of stem cells in post-stroke healing.

\section{Key words:}

1. Stroke

2. Stem Cells

3. Neuroprotection

4. Therapeutics

*Corresponding Author: Sorayya Ghasemi

E-mail: sorayya.ghasemi@gmail.com 


\title{
درمان سكتوُ مغزى مبتنى بر سلولهاى بنيادى
}

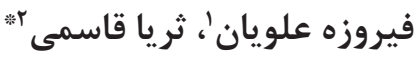

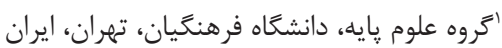

'مركز تحقيقات سلولى و مولكولى، يُوهشكده علوم يايه سلامت، دانشكاه علوم يزشكى شهركرد، شهركرد، ايران
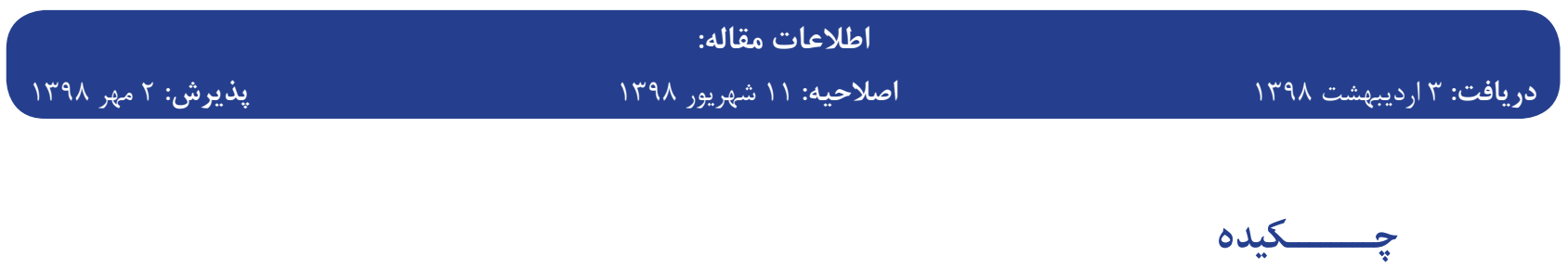

مقدمه: سلولهاى خود تجديد شونده و قابل تمايز يا سلولهاى بنيادى، سلولهايى با رتانسيل بانسيل بالا در

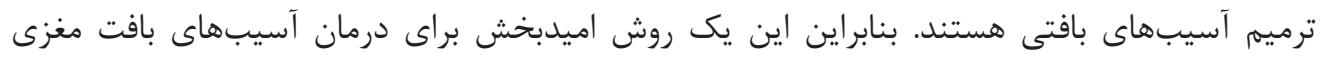

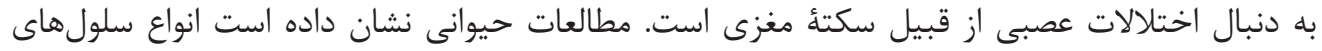

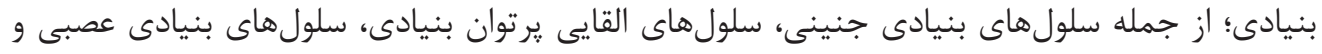

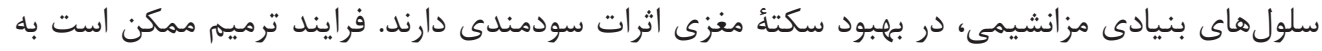

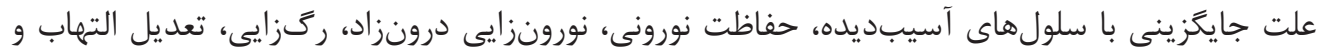

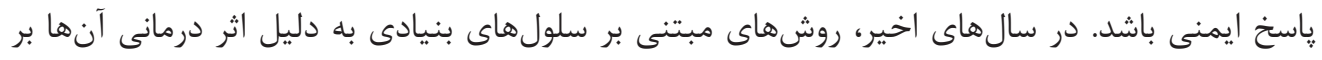

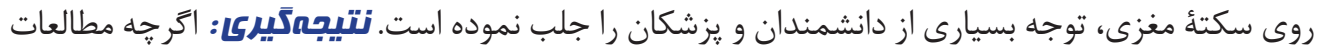

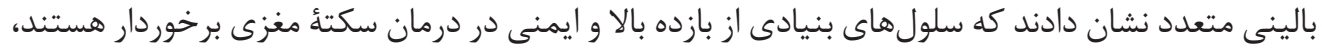

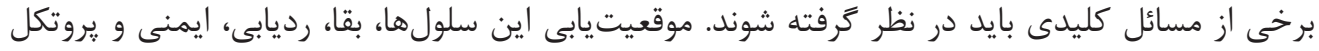

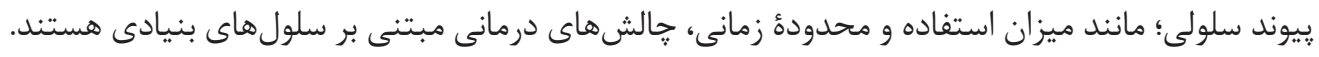

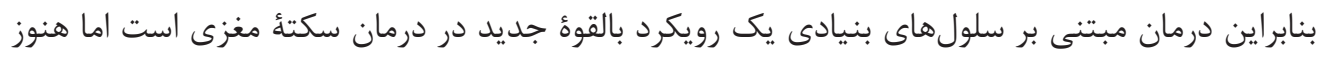

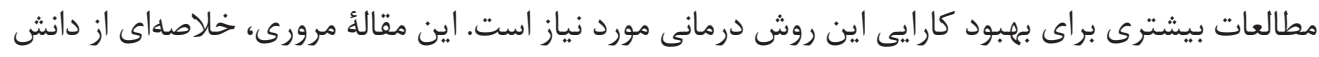

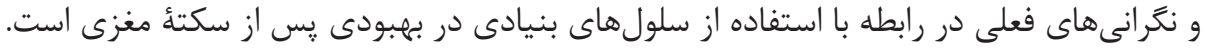

\footnotetext{
كليد وازهها:

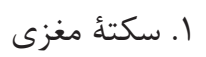

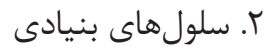

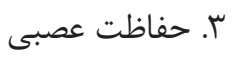

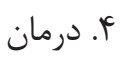




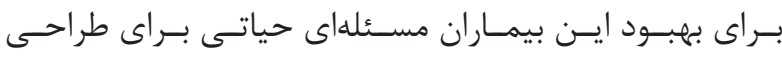

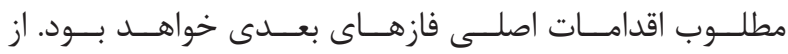

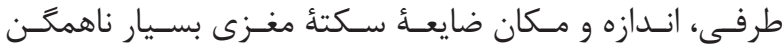

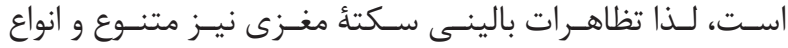

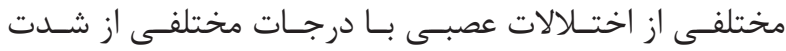

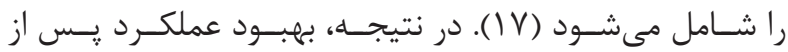

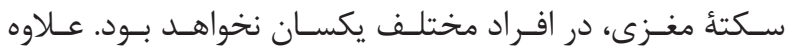

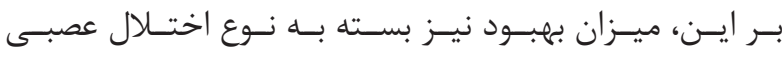

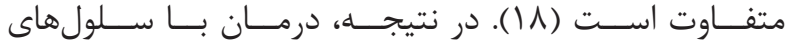

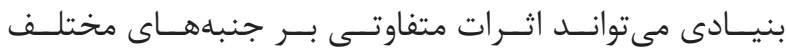

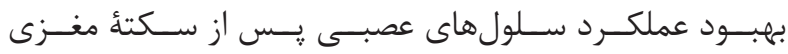

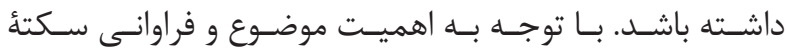

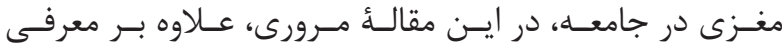

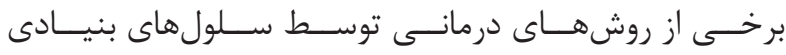

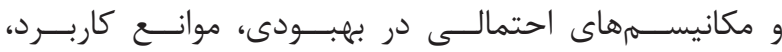

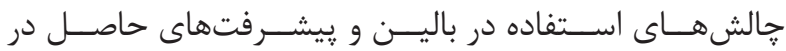

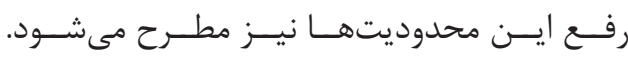

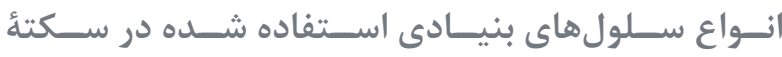
مغنـز

سـلول هاى بنيــادى بــا توانايـى تبديـلـ بــهـ عصـب و انواعـى از

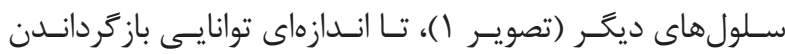

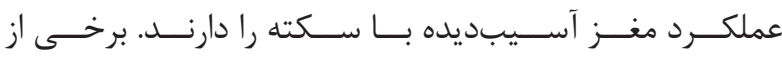

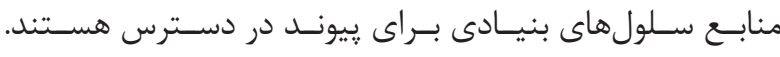

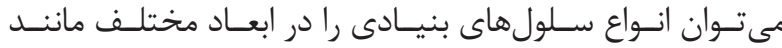

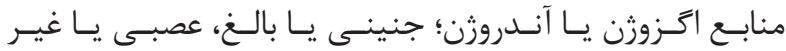

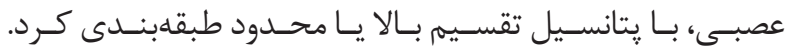

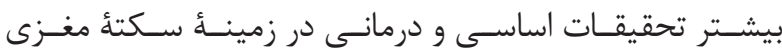

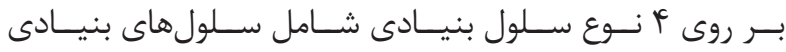

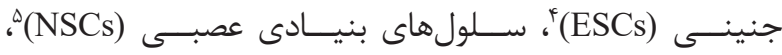

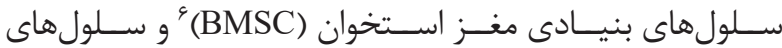

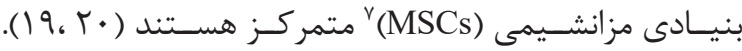
سلول هاى بنيادى جنينى

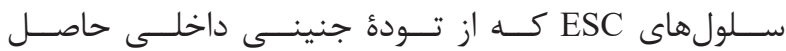

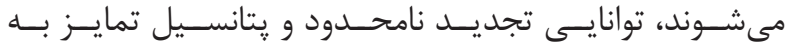

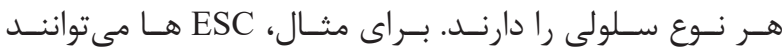

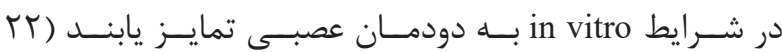

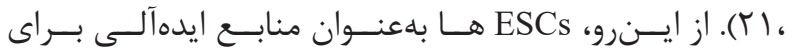

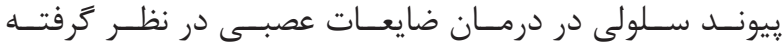

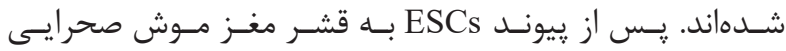

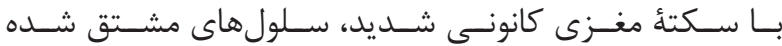

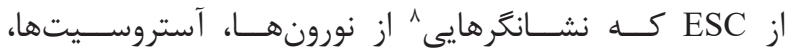

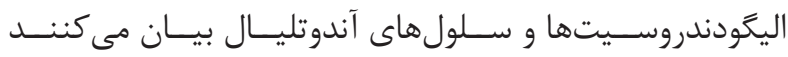

${ }^{1}$ Signaling

${ }^{2}$ Tissue plasminogen activator

${ }^{3}$ Stem cell therapy

${ }^{4}$ Embryonic stem cell

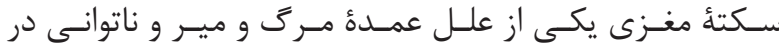

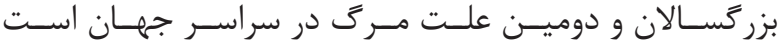

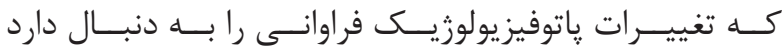

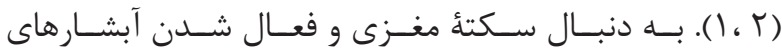

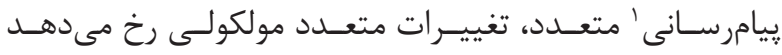

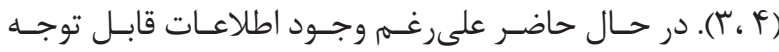

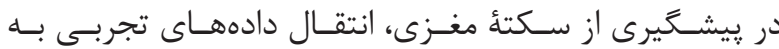

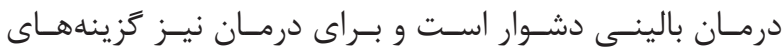

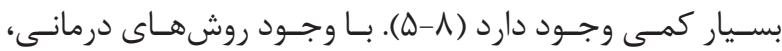

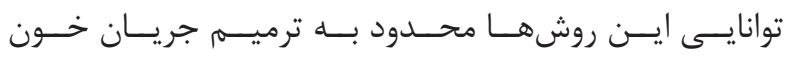

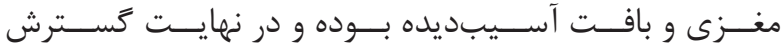

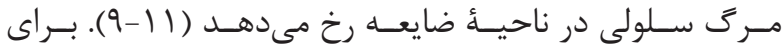

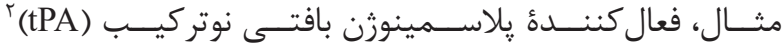

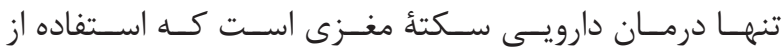

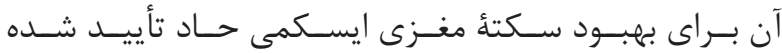

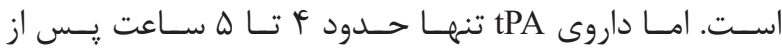

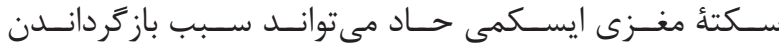

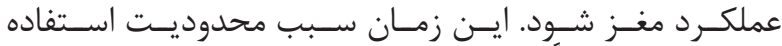

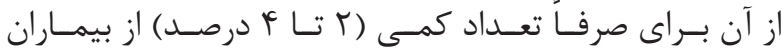

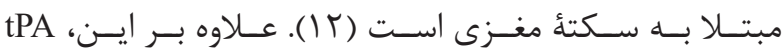

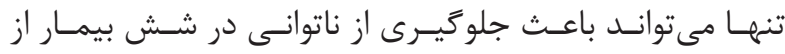

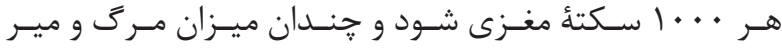

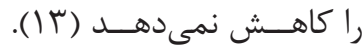

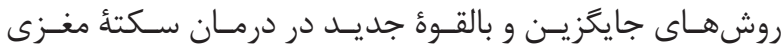

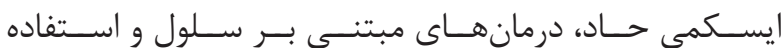

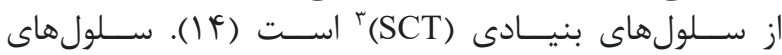

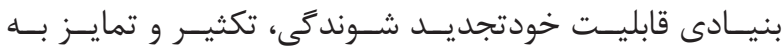

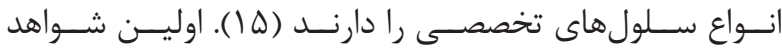

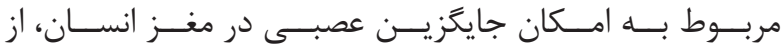

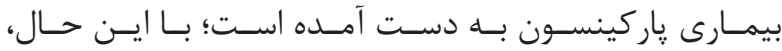

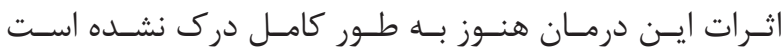

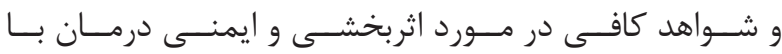

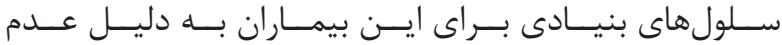

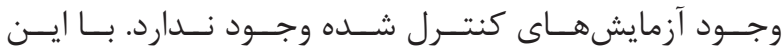

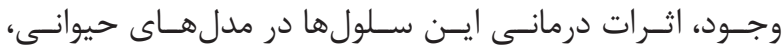

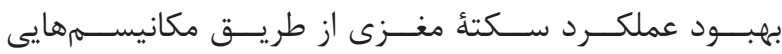

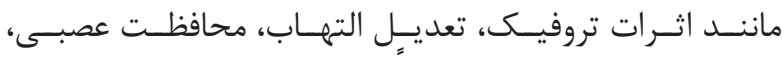

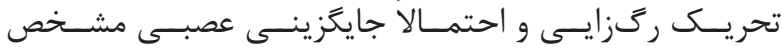

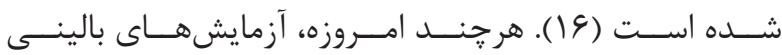

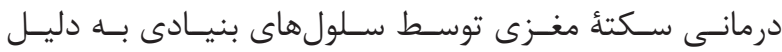

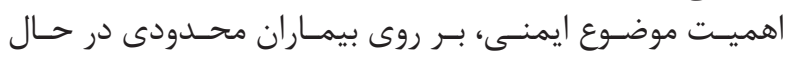

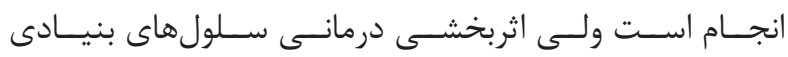

\footnotetext{
${ }^{5}$ Neural stem cell

${ }^{6}$ Bone marrow-derived stem cells

${ }^{7}$ Mesenchymal stem cell

${ }^{8}$ Marker
} 


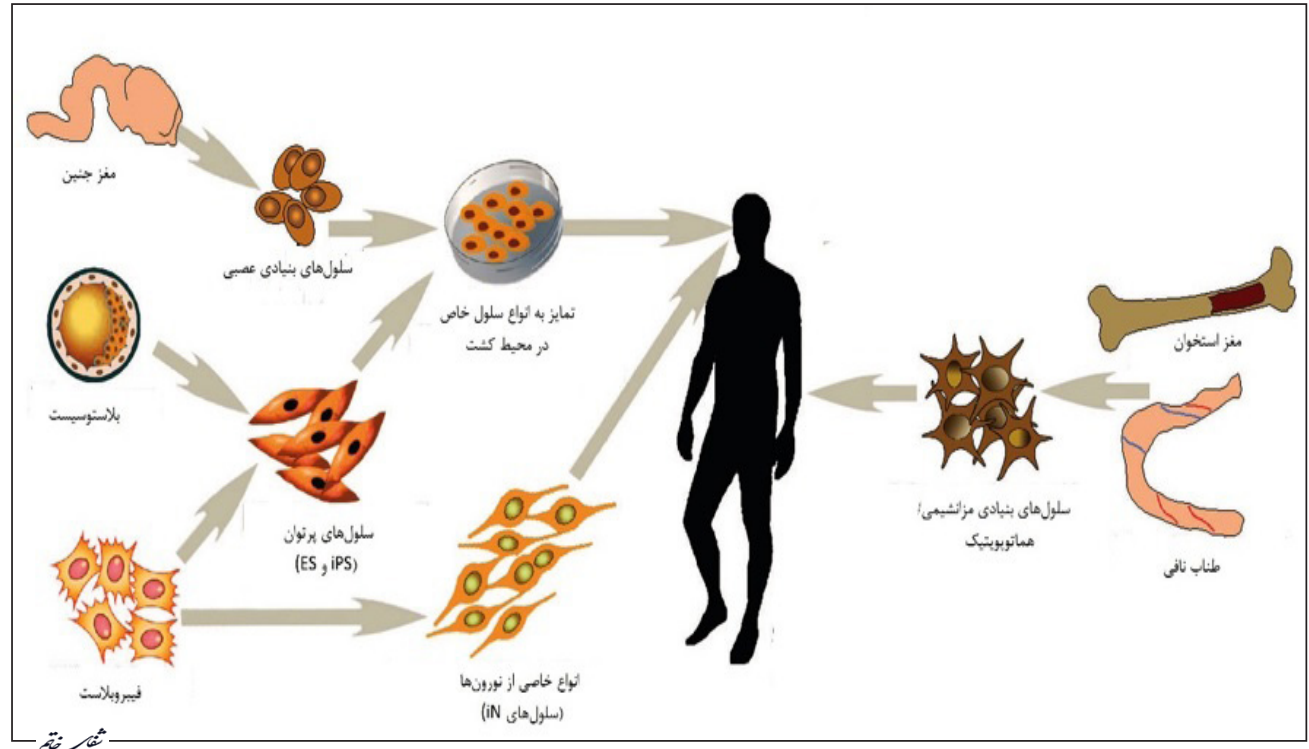

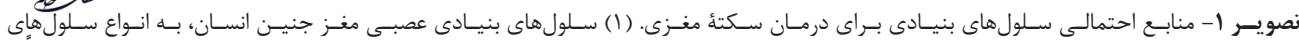

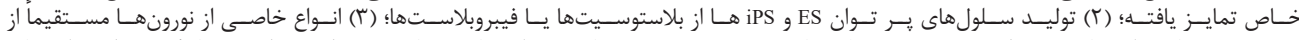

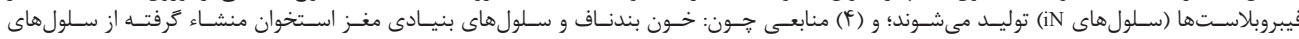

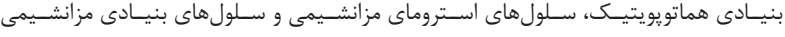

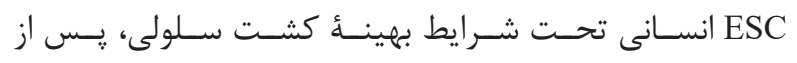

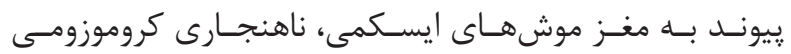

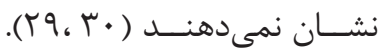

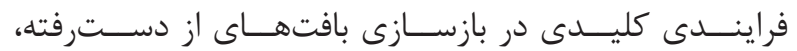

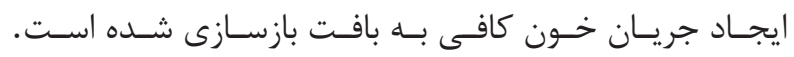

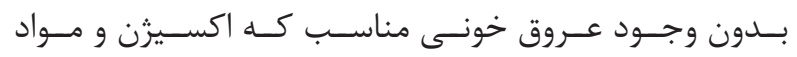

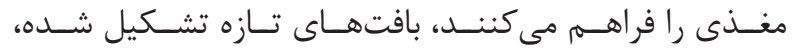

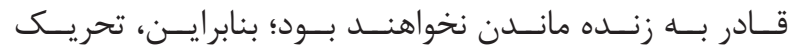

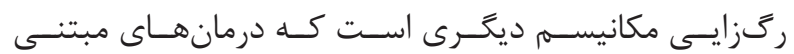

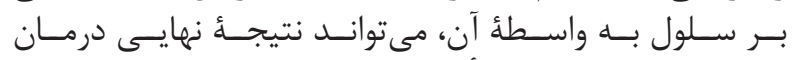

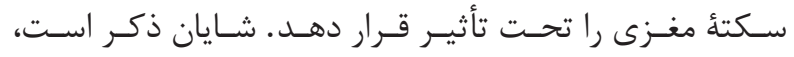

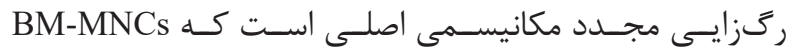

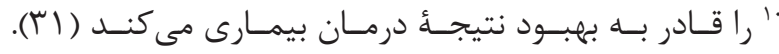

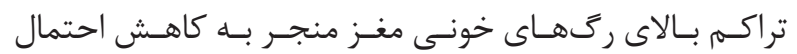

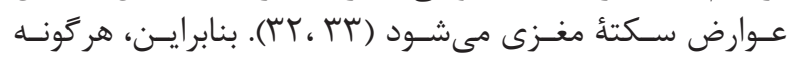

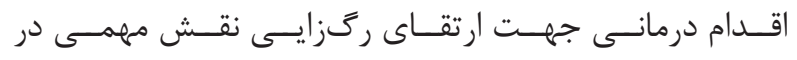

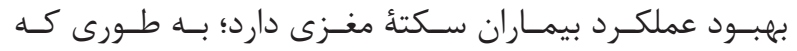

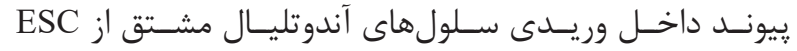

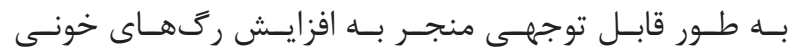

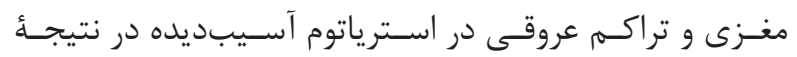

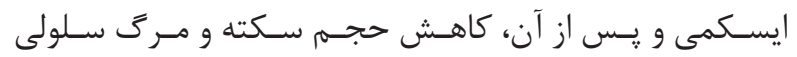

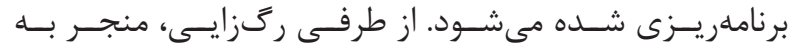

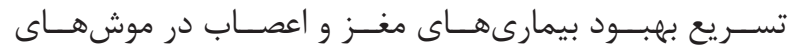

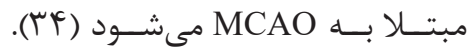
سلولهاى بنيادى عصبى القايى سـلولهاى بنيــادى يـــــــــوان القايسـى (iPSCs)" ابتـــدا از

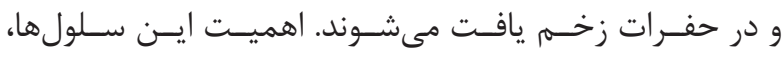

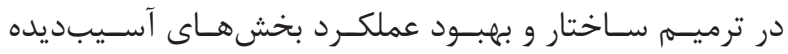

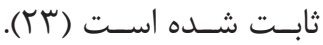

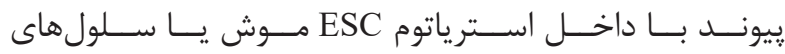

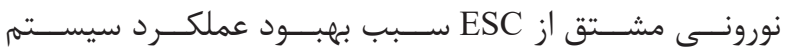

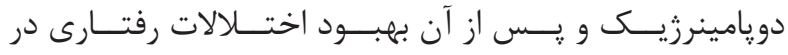

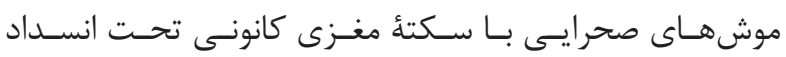

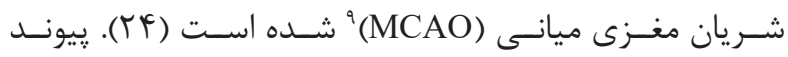

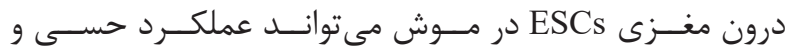

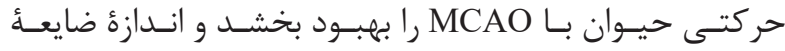

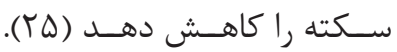

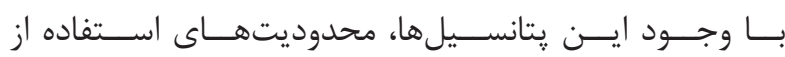

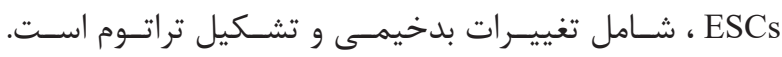

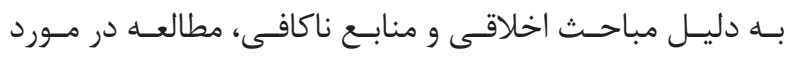

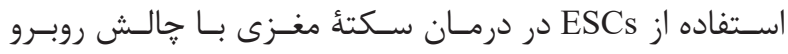

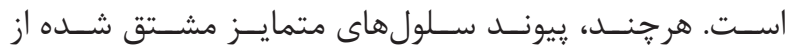

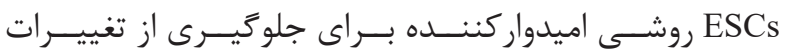

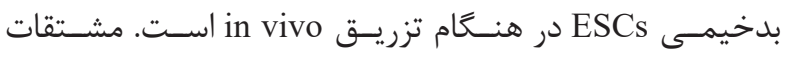

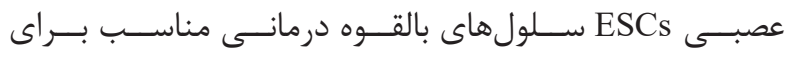

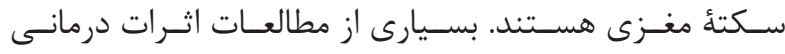

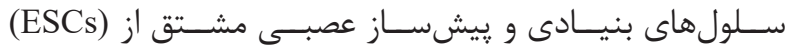

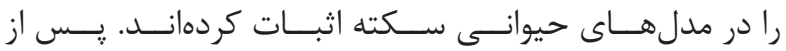

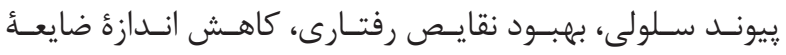

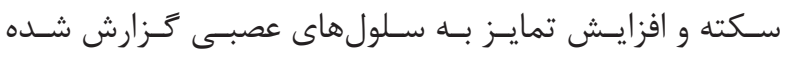

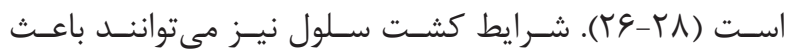

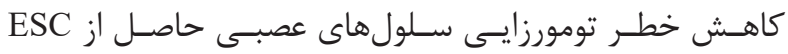

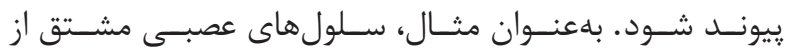

\footnotetext{
${ }^{9}$ Middle cerebral artery occlusion

${ }^{10}$ Intra-arterial bone marrow mononuclear cells

${ }^{11}$ Inducible pluripotent stem cells
} 


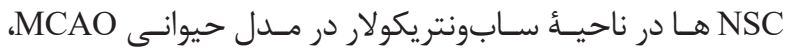

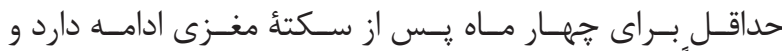

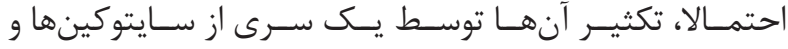

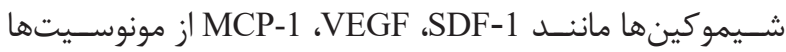

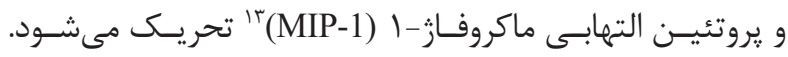

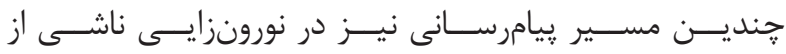

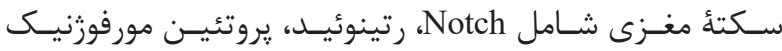

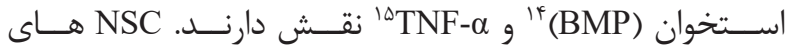

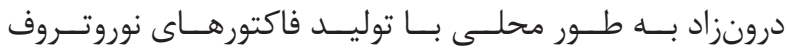

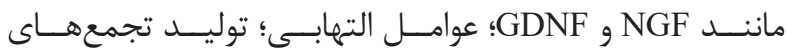

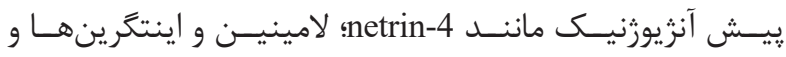

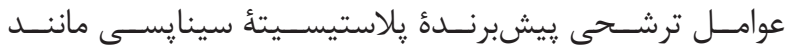

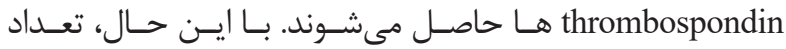

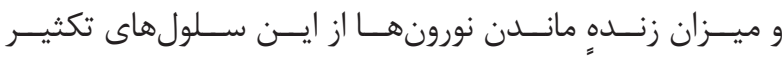

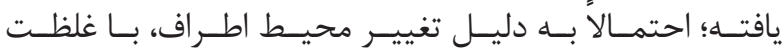

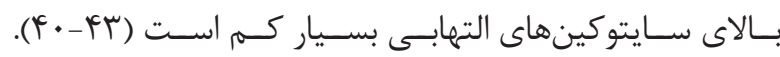

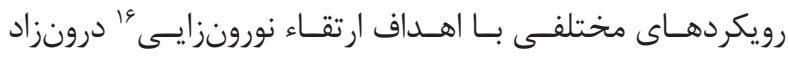

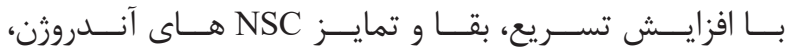

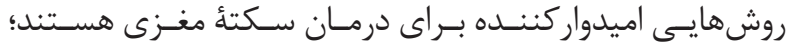

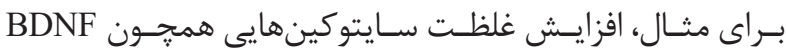

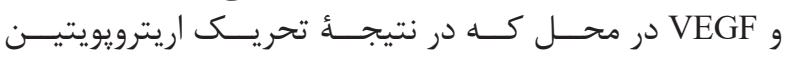

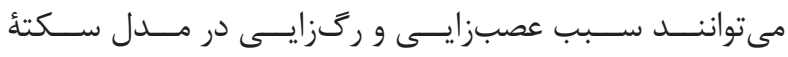

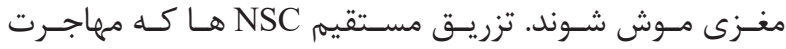

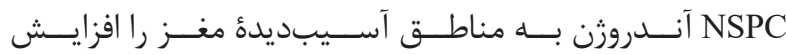

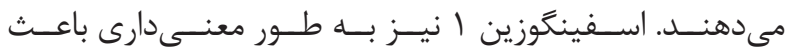

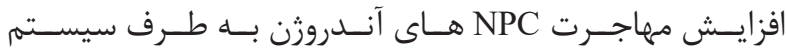

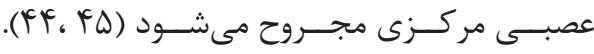

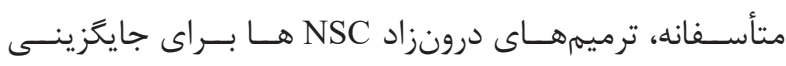

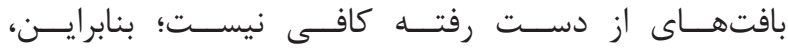

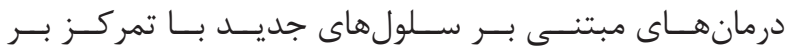

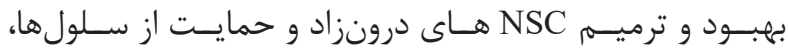

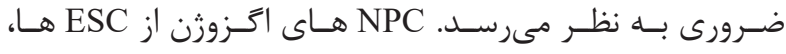

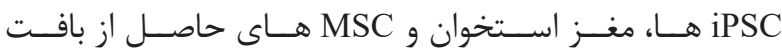

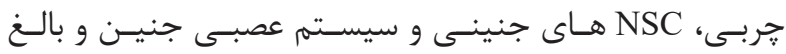

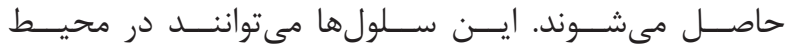

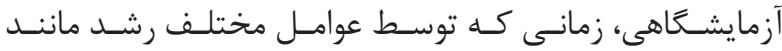

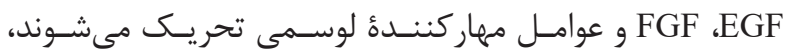

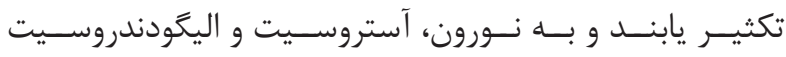

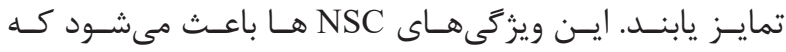

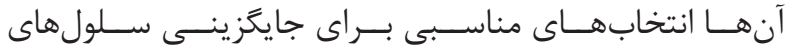

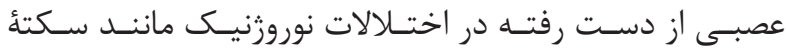

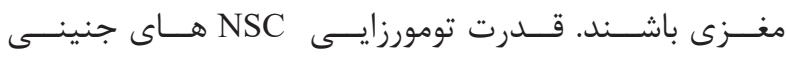

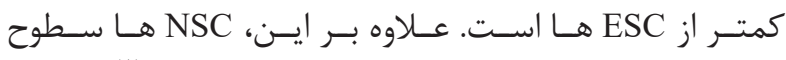

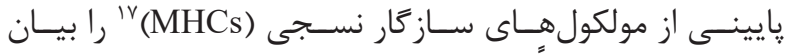

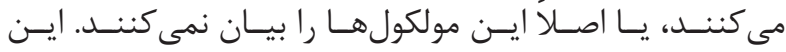

${ }^{12}$ Morphology

${ }^{13}$ Macrophage inflammatory proteins

${ }^{14}$ Bone morphogenetic protein

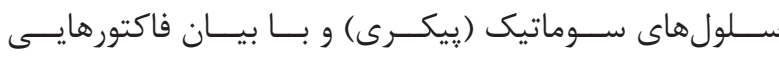

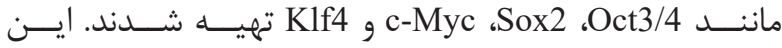

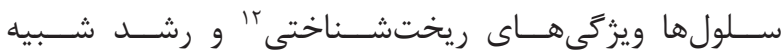

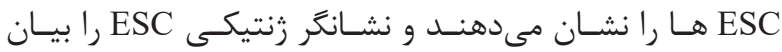

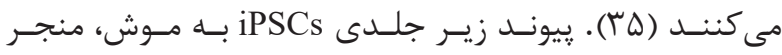

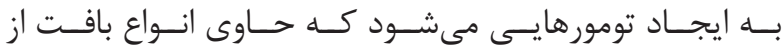

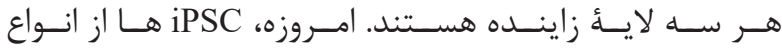

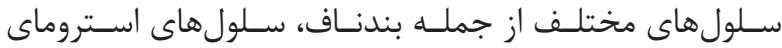

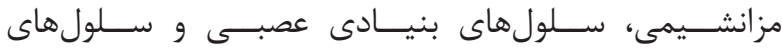

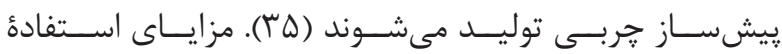

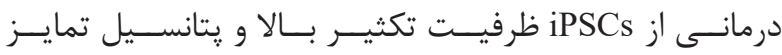

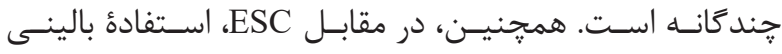

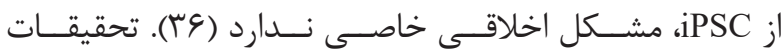

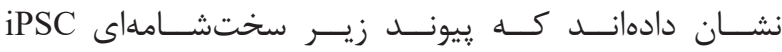

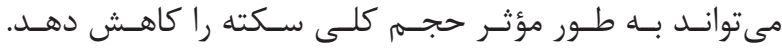

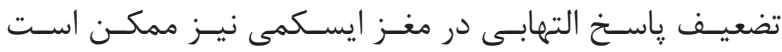

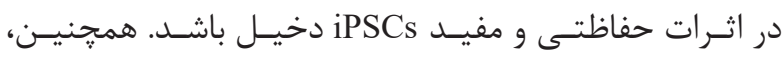

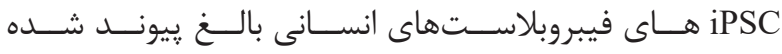

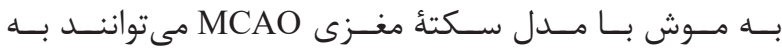

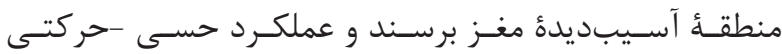

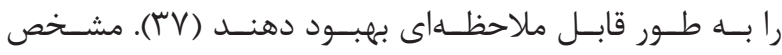

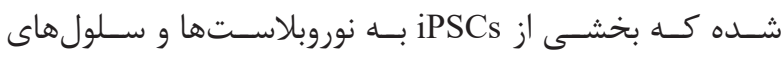

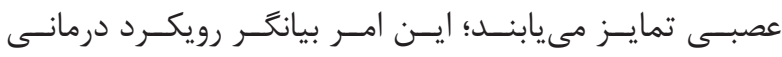

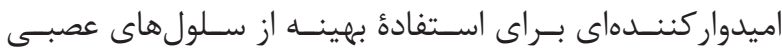

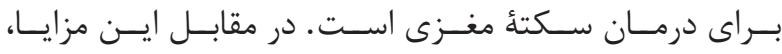

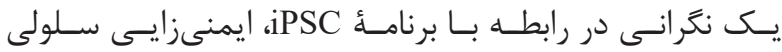

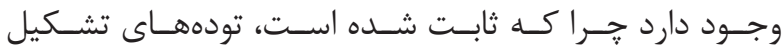

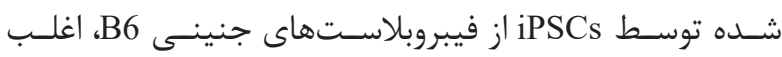

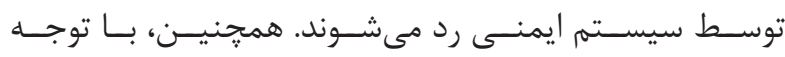

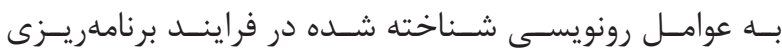

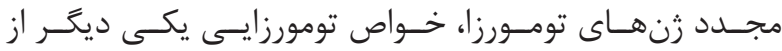

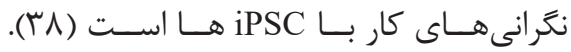

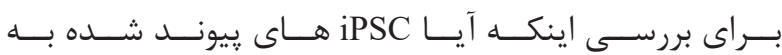

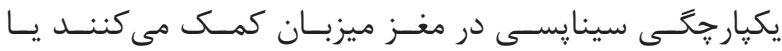

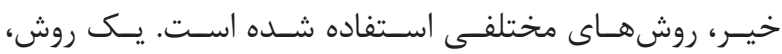

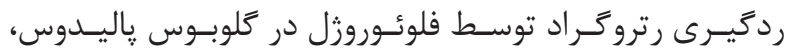

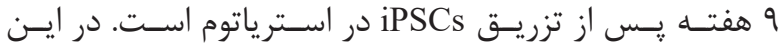

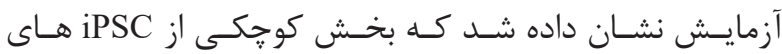

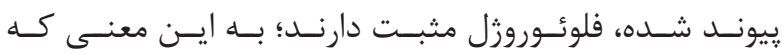

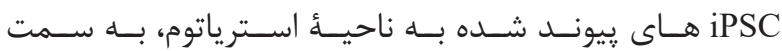

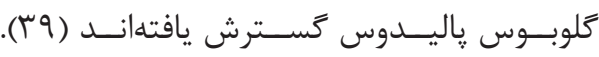
سلول هاى بنيادى عصبى ني

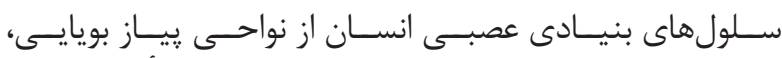

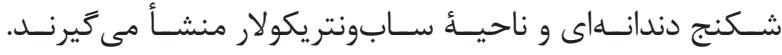

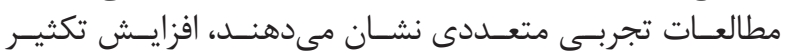

${ }^{15}$ Tumor necrosis factor alpha

${ }^{16}$ Neurogenesis

${ }^{17}$ Major histocompatibility complex 


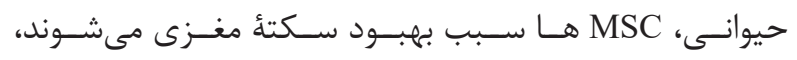

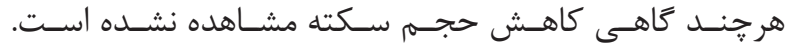

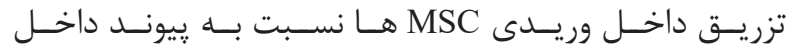

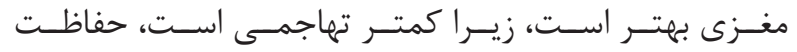

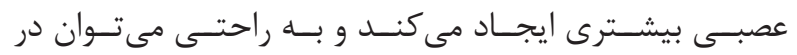

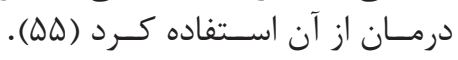

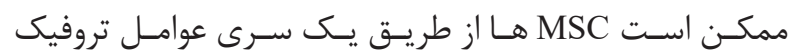

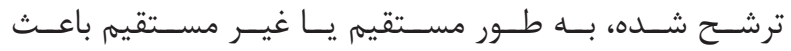

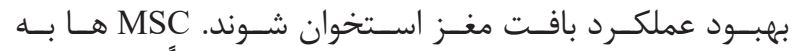

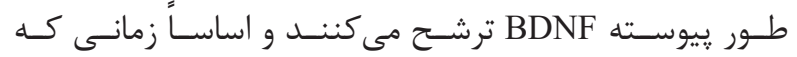

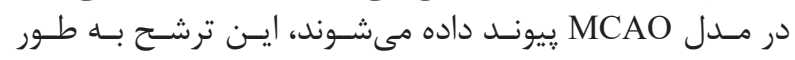

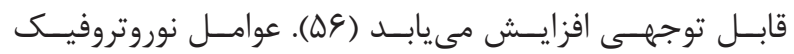

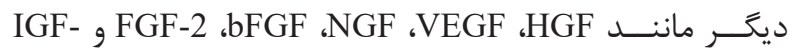

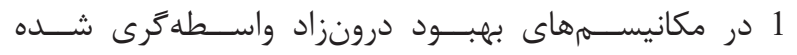

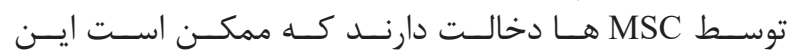

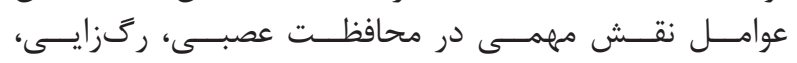

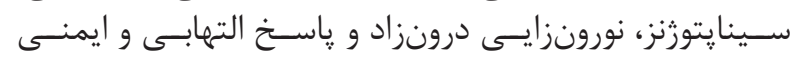

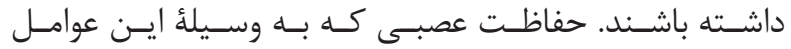

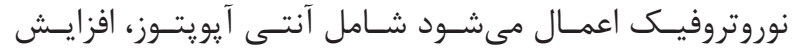

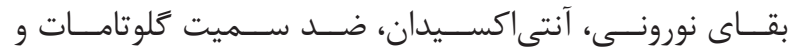

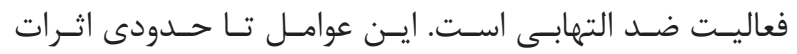

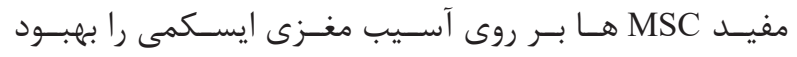

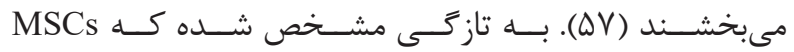

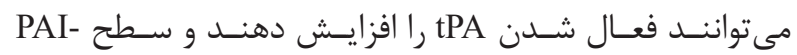
1

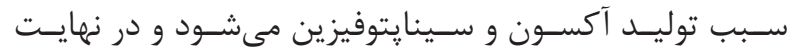

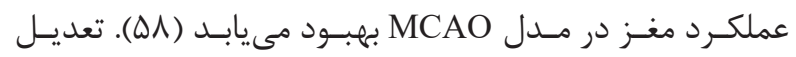

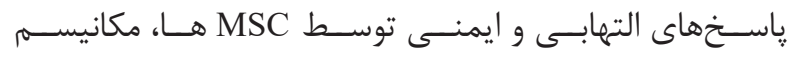

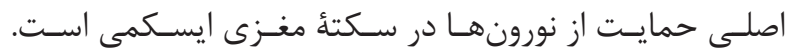

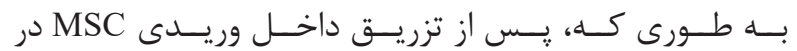

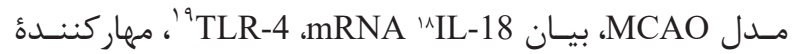

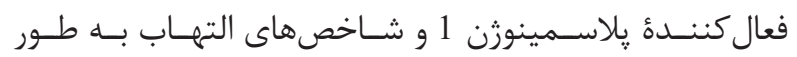
معنــى دارى كاهـش يافتـ (ه9).

سلولهاى بنيادى مشتق از خون و مغز استخوان

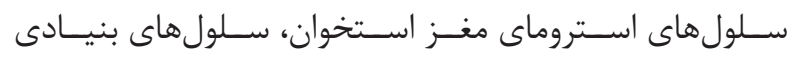

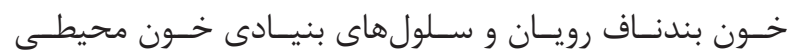

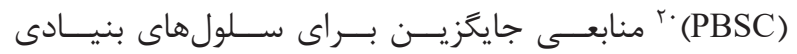

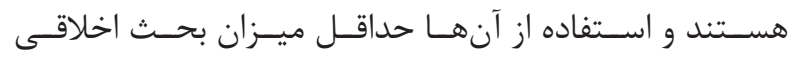

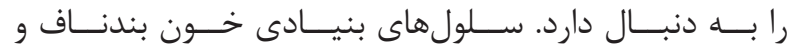

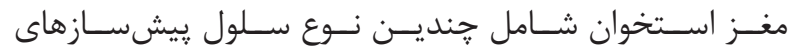

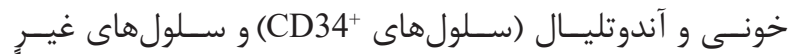

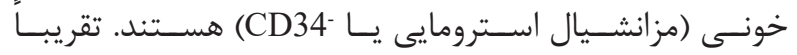

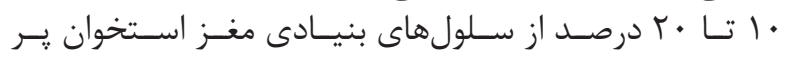

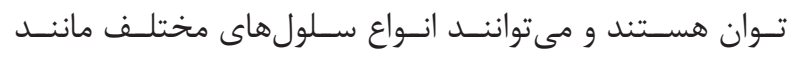

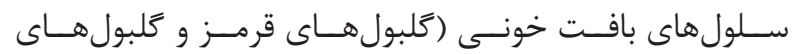

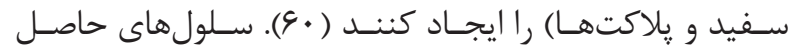

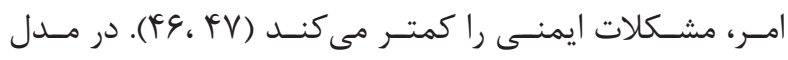

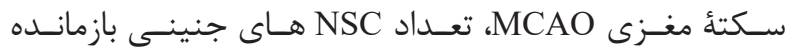

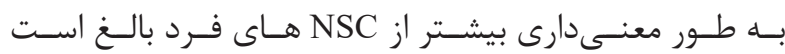

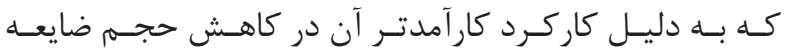

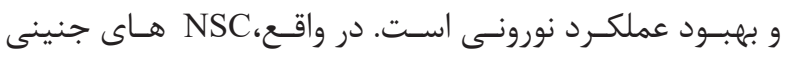

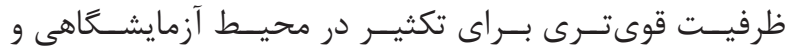

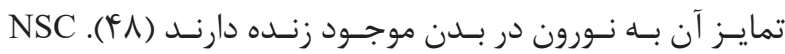

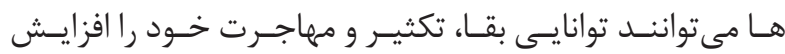

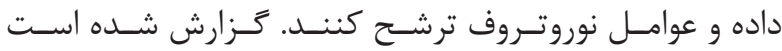

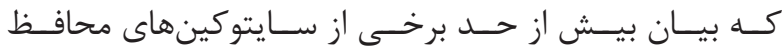

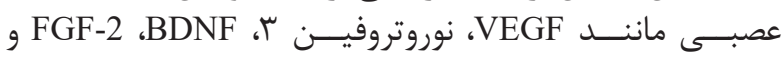

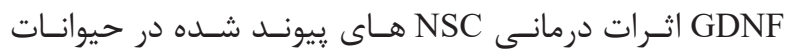

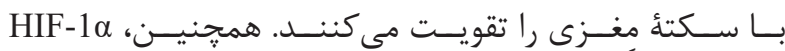

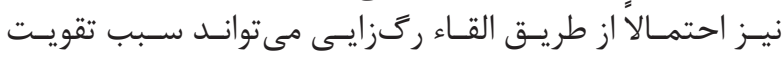

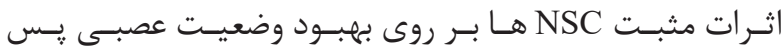

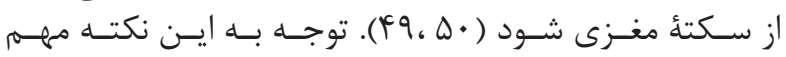

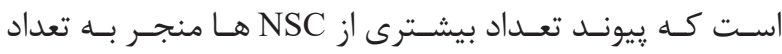

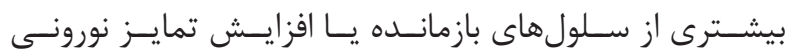

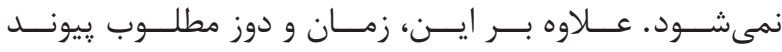

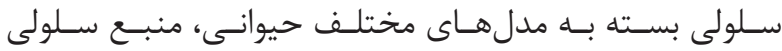

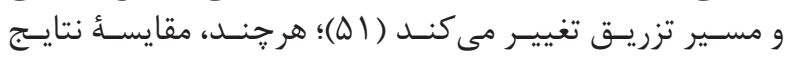

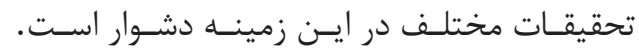

$$
\text { سلول هاى بنيادى مزانشيمى مي }
$$

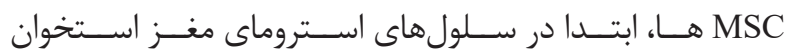

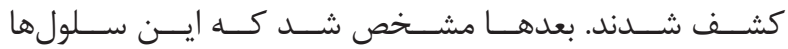

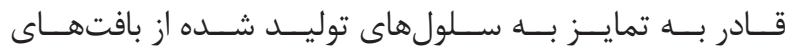

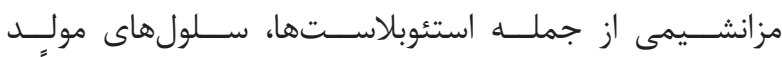

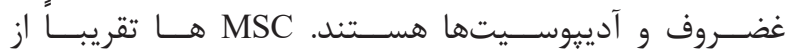

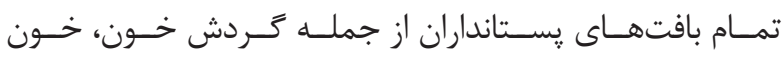

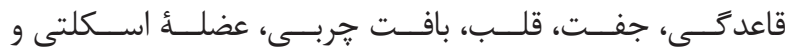

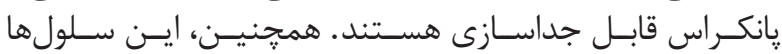

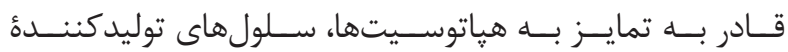

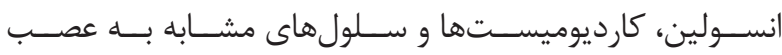

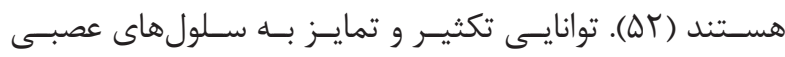

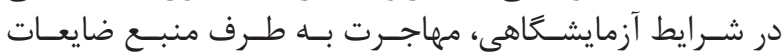

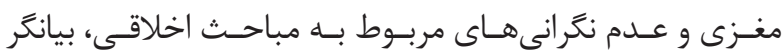

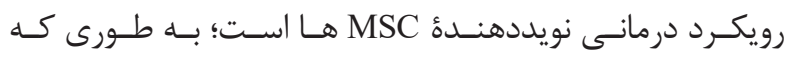

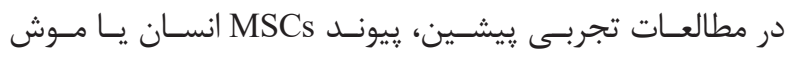

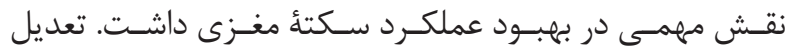

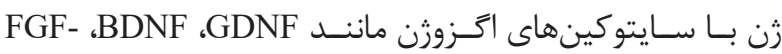

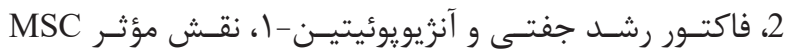

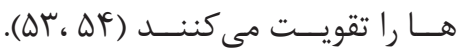

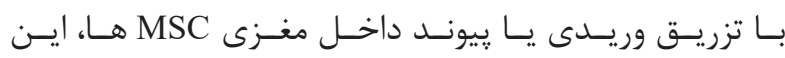

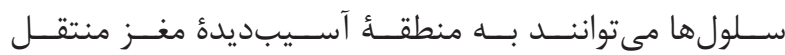

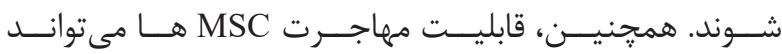

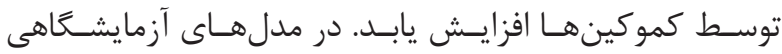

${ }^{18}$ Interleukin-18

${ }^{19}$ Toll-like receptor 4

${ }^{20}$ Peripheral blood stem cells 


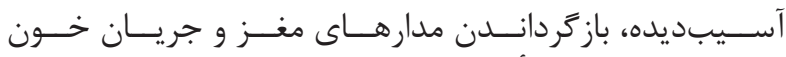

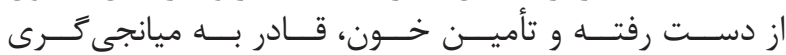

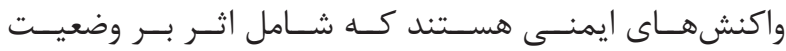

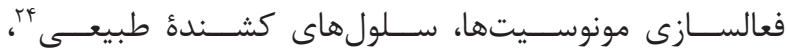

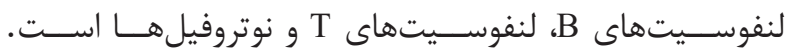

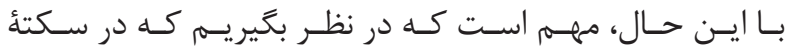

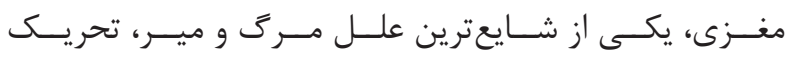

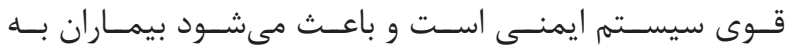

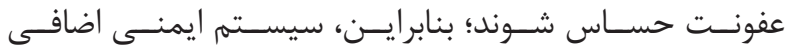

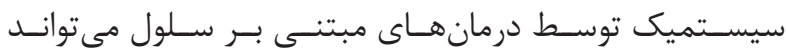

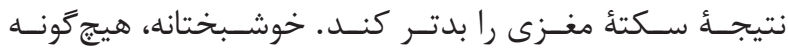

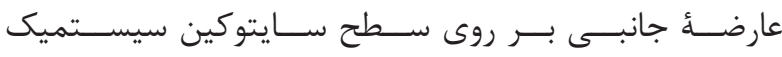

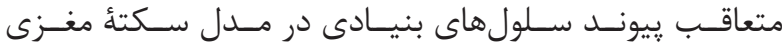

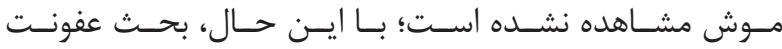

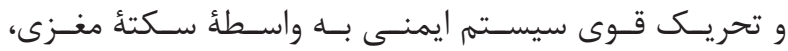

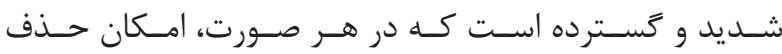

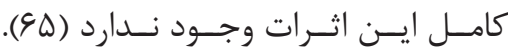

\section{بقاى سلولها}

عوامـل متعـددى ممكــن اســت بــر بقــاى سـلولها در فــاز

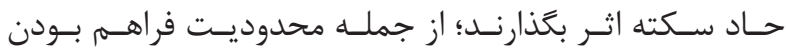

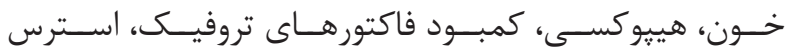

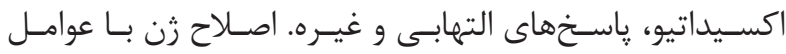

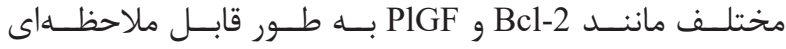

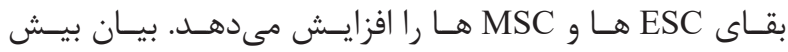

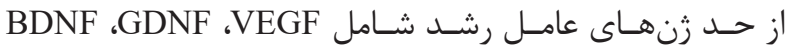

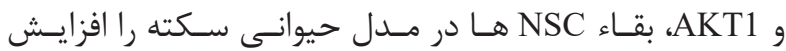

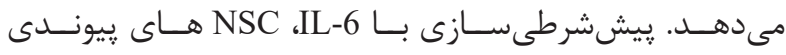

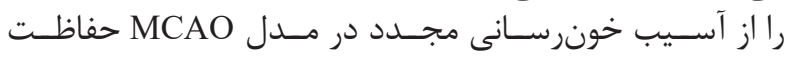

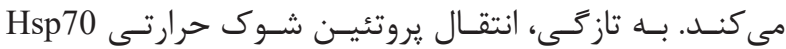

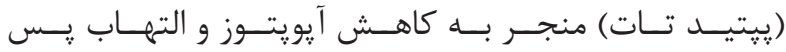

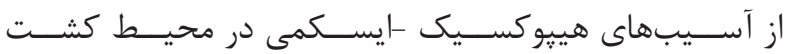

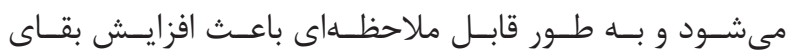

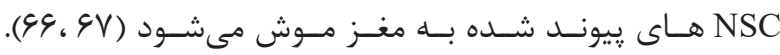

\section{رديابى سلول و زن}

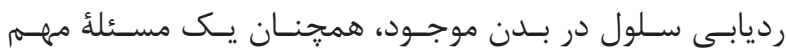

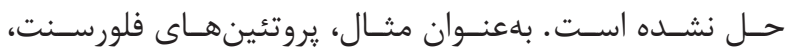

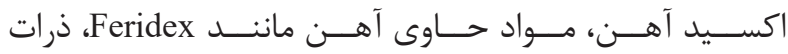

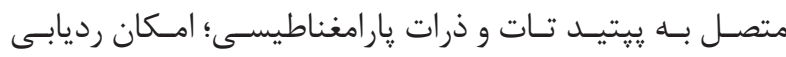

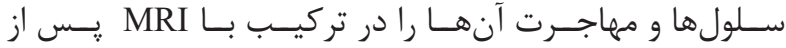

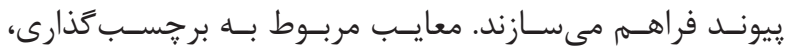

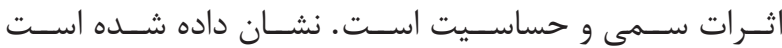

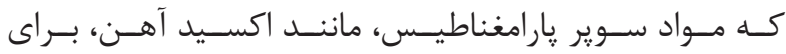

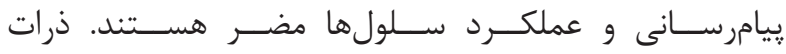

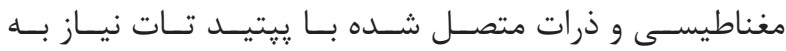

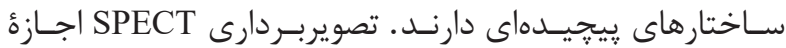

${ }^{21}$ Colony stimulating factors

${ }^{22}$ Stem cell factor

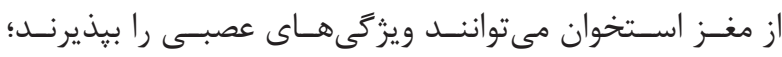

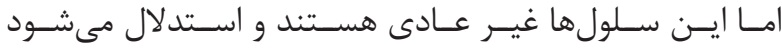

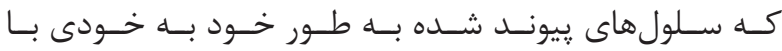

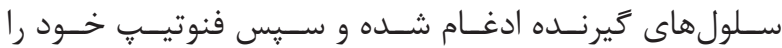

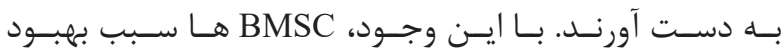

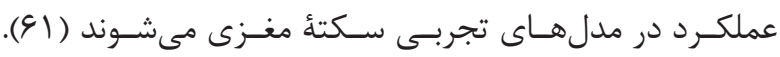

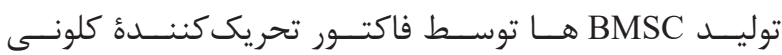
(CSF)

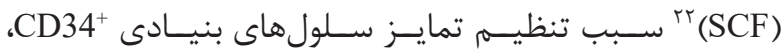

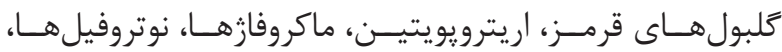

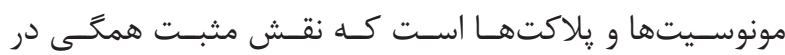

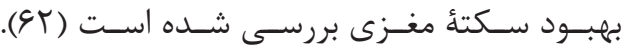
جالش هاى ״يش روى درمان

\section{مهاجرت و جاعيرى مناسب و هدف}

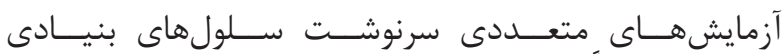

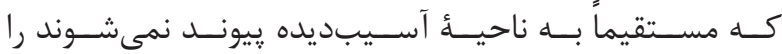

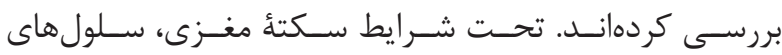

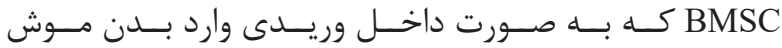

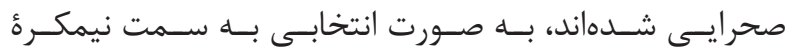

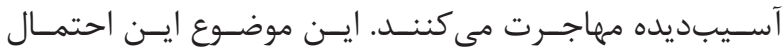

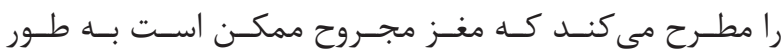

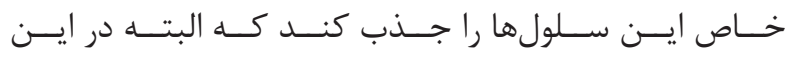

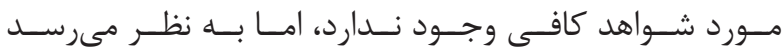

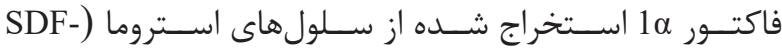

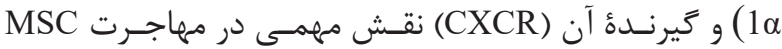

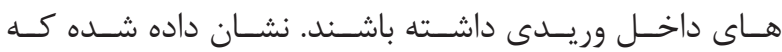

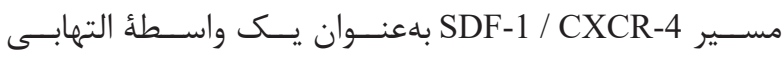

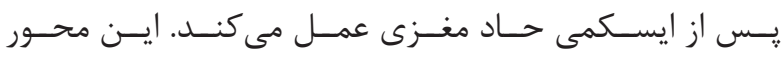

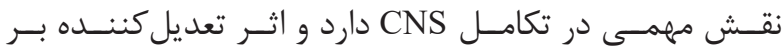

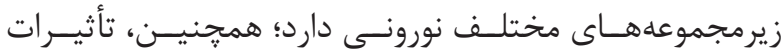

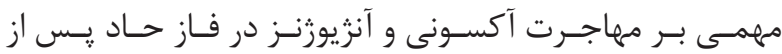

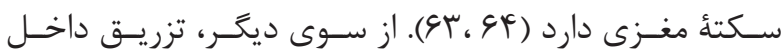

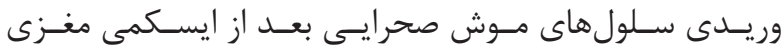

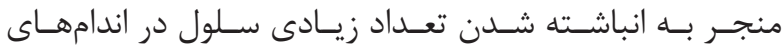

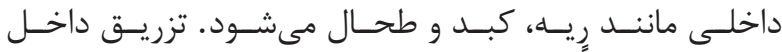

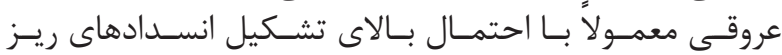

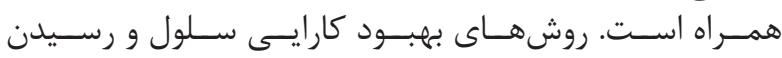

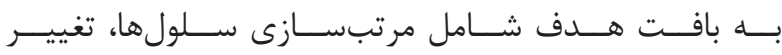

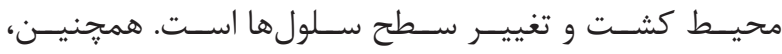

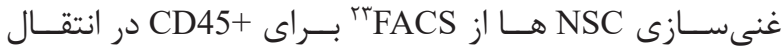

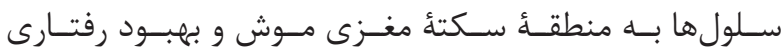

كمــك مى كنـــد (li (l).

$$
\text { واكنش ايمنى }
$$

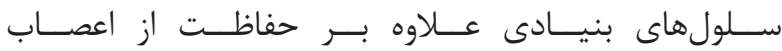

\footnotetext{
${ }^{23}$ Anti-human CD45 antibody for flow cytometry

${ }^{24}$ Natural killer cells
} 


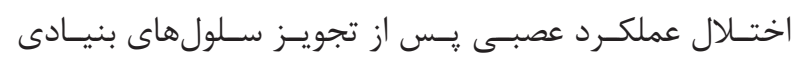

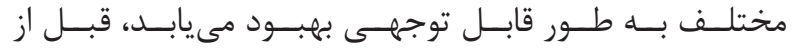

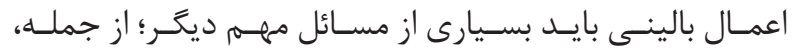

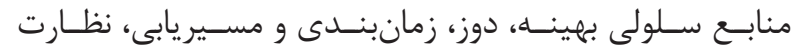

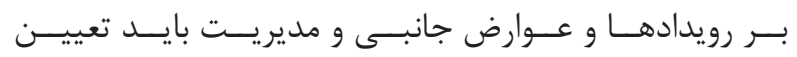

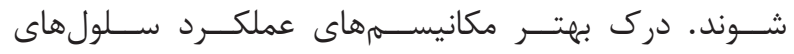

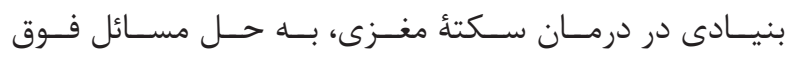
كمــك مى كنــد.

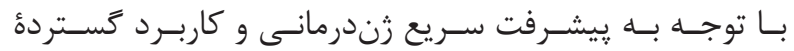

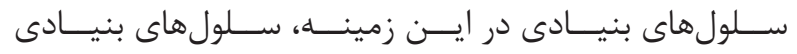

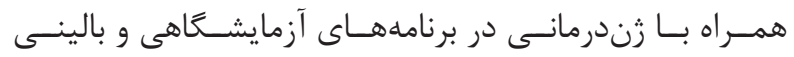

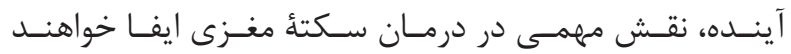

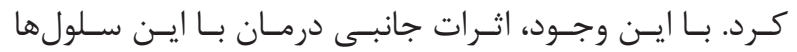

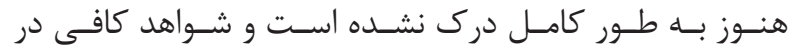

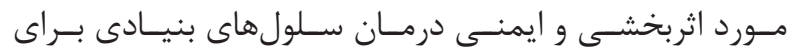

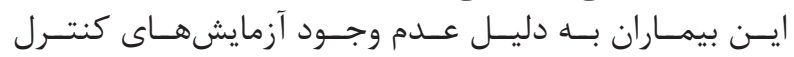

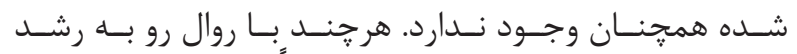

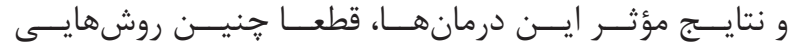

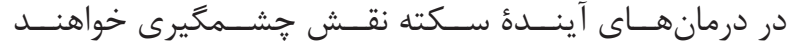

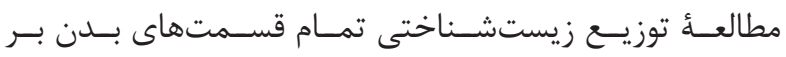

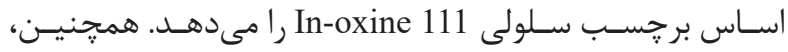

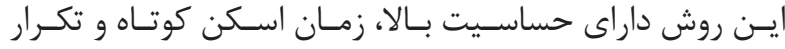

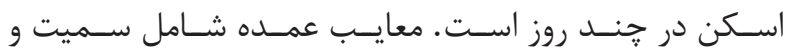

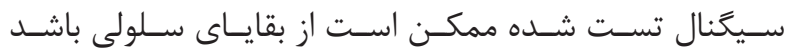

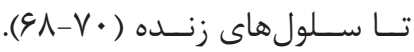

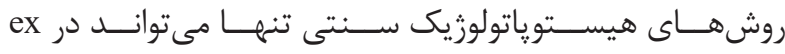

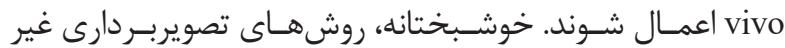

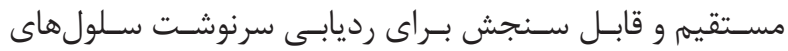

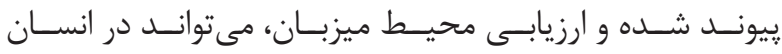

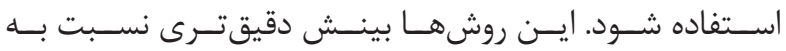

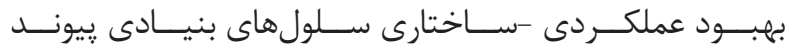

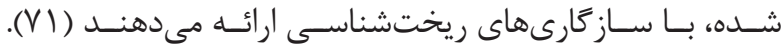

نتيجه

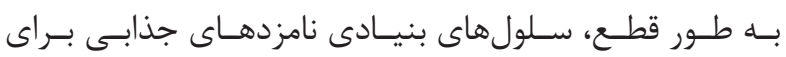

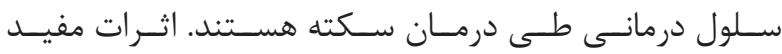

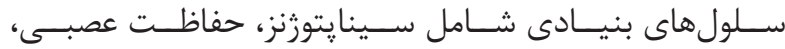

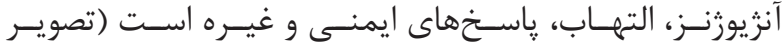

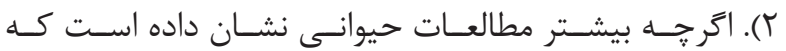

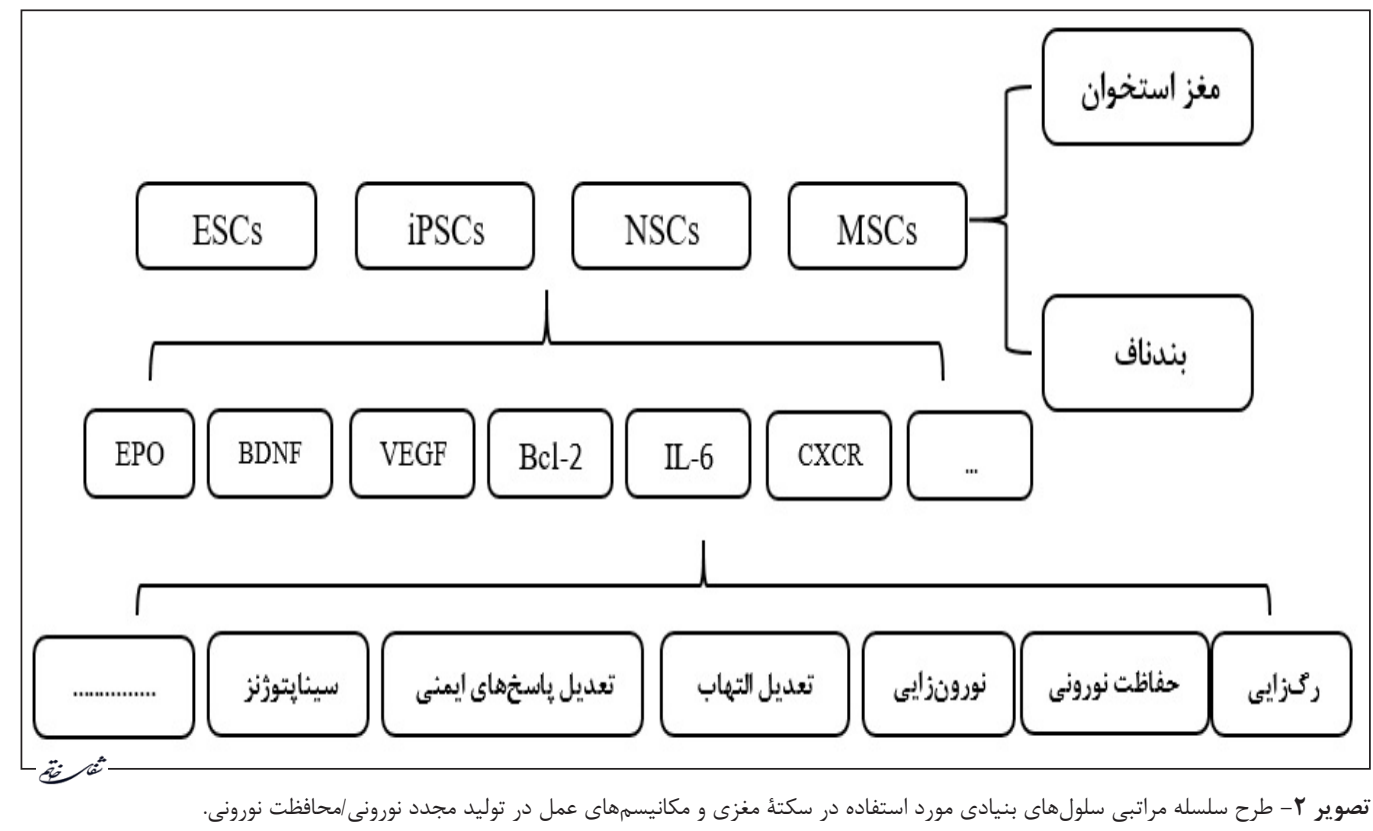


1. Alavian F, Hajizadeh S, Bigdeli MR, Javan M. Effect of intermittent normobaric hyperoxia and protein kinase $\mathrm{C}$ activity on blood-brain barrier permeability. Journal of Shahrekord University of Medical Sciences. 2012; 14(3): 40-50.

2. Behzad E, Zargaran A, Karimi M, Ghabaee M. P 37: Prescribing pepper for stroke treatment. Shefaye Khatam. 2017; 5(2): 68.

3. Alavian F, Hajizadeh S, Bigdeli MR, Javan M. The role of protein kinase $\mathrm{C}$ in ischemic tolerance induced by hyperoxia in rats with stroke. Excli Journal. 2012; 11: 188-97.

4. Alavian F, Hajizadeh S, Javan M, Mazloom R. Evaluation of ERK activity on Ischemic Toleranceinduced by Preconditioning with Intermittent Normobaric Hyperoxia in the Rat Model of Stroke. Arak Medical University Journal (AMUJ). 2017; 20(123): 41-53.

5. Alavian F, Hajizadeh S, Bigdeli MR, Bayat GR, Javan M. Evaluation of UCP 2 expression in the phenomenon of ischemic resistance induced by alternating normobaric hyperoxia in a rat model of stroke. Physiology and Pharmacology. 2012; 16(1): 54-61.

6. Alavian F, Hajizadeh S, Javan M, Bigdeli MR. Effects of preconditioning with intermittent normobaric hyperoxia on TNFR 1 and TNFR 2 expression in the rat brain. Physiology and Pharmacology. 2017; 21(2): 110-9.

7. Alavian F, Ghiasvand S. Protective effects of jujube extract against permeability of bloodbrain barrier, and the activity of glutathione peroxidase and catalase in stroke model. Journal of Isfahan Medical School. 2018; 36(475): 379-85.

8. Alavian F. Hypothermia and stroke: pros and cons. Shefaye Khatam. 2019; 7(2): 83-98.

9. Khorrami MB, Forouzanfar F, Sadeghnia HR, Sahab Negah S. The role of cannabinoids in ischemia stroke. Shefaye Khatam. 2017; 5(2): 179.

10. Alavian F, Ghiasvand S. Neuroprotective effects of stachys lavandulifolia hydroalcoholic extract on size of cerebral ischemia, blood-brain barrier permeability and edema volume in rat stroke model. Journal of Arak University of Medical Sciences. 2019; 21(7): 92-101.

11. Kamandi N, Akhgari N, Sahab Negah S. Effect of glycoprotein iib/iiia inhibition on acute ischemic stroke injuries. Shefaye Khatam. 2017; 5(2): 180.
منابع

12. Molina CA. Reperfusion therapies for acute ischemic stroke: current pharmacological and mechanical approaches. Stroke. 2011; 1(1): 16-9.

13. Hacke W, Donnan G, Fieschi C, Kaste M, Broderick JP, Brott T, et al. Association of outcome with early stroke treatment: pooled analysis of ATLANTIS, ECASS, and NINDS rt-PA stroke trials. Lancet. 2004; 363(9411): 76874.

14. Jeong H, Yim HW, Cho Y-s, Kim Y-I, Jeong S-N, Kim H-b, et al. Efficacy and safety of stem cell therapies for patients with stroke: a systematic review and single arm meta-analysis. International Journal of Stem Cells. 2014; 7(2): 63-9.

15. Sandu RE, Balseanu AT, Bogdan C, Slevin M, Petcu E, Popa-Wagner A. Stem cell therapies in preclinical models of stroke. Is the aged brain microenvironment refractory to cell therapy? Exp Gerontol. 2017; 94: 73-7.

16. Zhang ZG, Chopp M. Neurorestorative therapies for stroke: underlying mechanisms and translation to the clinic. Lancet Neurol. 2009; 8(5): 491-500.

17. Alavian F, Hajizadeh S, Javan M, Bigdeli MR. Evaluation of Hif1A expression in ischemic tolerance induced by intermittent normobaric hyperoxia in the rat model of stroke. Journal of Sabzevar University of Medical Sciences. 2012; 287-95.

18. Cramer SC, Koroshetz WJ, Finklestein SP. The case for modality-specific outcome measures in clinical trials of stroke recovery-promoting agents. Stroke. 2007; 38(4): 1393-5.

19. Chan HH, Wathen CA, Ni M, Zhuo S. Stem cell therapies for ischemic stroke: current animal models, clinical trials and biomaterials. RSC Adv. 2017; 7(30): 18668-80.

20. Yamaguchi S, Kuroda S, Kobayashi H, Shichinohe H, Yano S, Hida K, et al. The effects of neuronal induction on gene expression profile in bone marrow stromal cells (BMSC)-a preliminary study using microarray analysis. Brain Research. 2006; 1087(1): 15-27.

21. Zhang S-C, Wernig M, Duncan ID, Brustle O, Thomson JA. In vitro differentiation of transplantable neural precursors from human embryonic stem cells. Nature Biotechnology. 2001; 19(12): 1129-33.

22. Ying Q-L, Stavridis M, Griffiths D, Li M, Smith A. Conversion of embryonic stem cells into neuroectodermal precursors in adherent monoculture. 


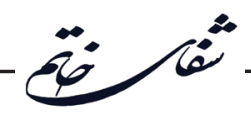

Nature Biotechnology. 2003; 21(2): 183-6.

23. Wei L, Cui L, Snider BJ, Rivkin M, Steven SY, Lee C-S, et al. Transplantation of embryonic stem cells overexpressing $\mathrm{Bcl}-2$ promotes functional recovery after transient cerebral ischemia. Neurobiology of Disease. 2005; 19(1-2): 183-93.

24. Yanagisawa D, Qi M, Kim D-h, Kitamura Y, Inden M, Tsuchiya D, et al. Improvement of focal ischemia-induced rat dopaminergic dysfunction by striatal transplantation of mouse embryonic stem cells. Neuroscience Letters. 2006; 40791): 74-9.

25. Tae-Hoon L, Yoon-Seok L. Transplantation of mouse embryonic stem cell after middle cerebral artery occlusion. Acta Cirurgica Brasileira. 2012; 27(4): 333-9.

26. Hao L, Zou Z, Tian H, Zhang Y, Zhou H, Liu L. Stem cell-based therapies for ischemic stroke. BioMed Research International. 2014; 2014.

27. Yousuf Y, Amini-Nik S, Jeschke MG. Use of stem cells in acute and complex wounds. pancreas, kidney and skin regeneration. Pancreas, Kidney and Skin Regeneration. 2017; 195-226.

28. Dixon KJ, Theus MH, Nelersa CM, Mier J, Travieso LG, Yu T-S, et al. Endogenous neural stem/progenitor cells stabilize the cortical microenvironment after traumatic brain injury. Journal of Neurotrauma. 2015; 32(11): 753-64.

29. Daadi MM, Maag A-L, Steinberg GK. Adherent self-renewable human embryonic stem cell-derived neural stem cell line: functional engraftment in experimental stroke model. PloS One. 2008; 3(2).

30. Alizadeh A, Ghasemi S. Importance of analyzing the genomic instability in stem cell-based therapies. Journal of Isfahan Medical School. 2016; 34(383): 572-9.

31. Nakano-Doi A, Nakagomi T, Fujikawa M, Nakagomi N, Kubo S, Lu S, et al. Bone marrow mononuclear cells promote proliferation of endogenous neural stem cells through vascular niches after cerebral infarction. Stem Cells. 2010; 28(7): 1292-302.

32. Baker EW, Kinder HA, West FD. Neural stem cell therapy for stroke: A multimechanistic approach to restoring neurological function. Brain and Behavior. 2019; 9(3): e01214.

33. Kokaia Z, Llorente IL, Carmichael ST. Customized brain cells for stroke patients using pluripotent stem cells. Stroke. 2018; 49(5): 1091-8.

34. Oyamada N, Itoh H, Sone M, Yamahara K, Miyashita
$\mathrm{K}$, Park K, et al. Transplantation of vascular cells derived from human embryonic stem cells contributes to vascular regeneration after stroke in mice. Journal of Translational Medicine. 2008; 6(1): 54.

35. Tat PA, Sumer H, Jones KL, Upton K, Verma PJ. The efficient generation of induced pluripotent stem (iPS) cells from adult mouse adipose tissue-derived and neural stem cells. Cell Transplantation. 2010; 19(5): 525-36.

36. Shtrichman R, Germanguz I, Eldor JI. Induced pluripotent stem cells (iPSCs) derived from different cell sources and their potential for regenerative and personalized medicine. Current Molecular Medicine. 2013; 13(5): 792-805.

37. Kokaia Z, Tornero D, Lindvall O. Transplantation of reprogrammed neurons for improved recovery after stroke. Progress in Brain Research. 2017; 231: 245-63.

38. Gore A, Li Z, Fung H-L, Young JE, Agarwal S, Antosiewicz-Bourget J, et al. Somatic coding mutations in human induced pluripotent stem cells. Nature. 2011; 471(7336): 63-7.

39. Tornero D, Wattananit S, GrÃ ,nning Madsen M, Koch P, Wood J, Tatarishvili J, et al. Human induced pluripotent stem cell-derived cortical neurons integrate in stroke-injured cortex and improve functional recovery. Brain. 2013; 136(12): 3561-77.

40. Wang X, Mao X, Xie L, Greenberg DA, Jin K. Involvement of notch1 signaling in neurogenesis in the subventricular zone of normal and ischemic rat brain in vivo. Journal of Cerebral Blood Flow \& Metabolism. 2009; 29(10): 1644-54.

41. Guzman R, De Los Angeles A, Cheshier S, Choi $\mathrm{R}$, Hoang S, Liauw J, et al. Intracarotid injection of fluorescence activated cell-sorted CD49d-positive neural stem cells improves targeted cell delivery and behavior after stroke in a mouse stroke model. Stroke. 2008; 39(4): 1300-6.

42. Sarmah D, Kaur H, Saraf J, Pravalika K, Goswami A, Kalia K, et al. Getting closer to an effective intervention of ischemic stroke: the big promise of stem cell. Translational Stroke Research. 2017; 1-19.

43. Kirschen GW, Sailor KA, Ge S. Structural plasticity induced by adult neurogenesis. The Rewiring Brain. 2017; 27-48.

44. Hermann DM, Peruzzotti-Jametti L, Schlechter J, Bernstock JD, Doeppner TR, Pluchino S. Neural precursor cells in the ischemic brainâ€"integration, cellular crosstalk, and consequences for stroke recovery. Frontiers in Cellular Neuroscience. 2014; 8: 1-9. 
45. Chen J, Venkat P, Zacharek A, Chopp M. Neurorestorative therapy for stroke. Frontiers in Human Neuroscience. 2014; 8: 1-12.

46. Lindvall O, Kokaia Z. Stem cell research in stroke: how far from the clinic? Stroke. 2011; 42(80).

47. Poulatsidou K-N, Lagoudaki R, Touloumi O, Kesidou E, Boziki M, Ravanidis S, et al. Immunophenotype of mouse cerebral hemispheres-derived neural precursor cells. Neuroscience Letters. 2016; 611: 33-9.

48. Koliatsos VE, Yan J, Johe KK. Survival, differentiation and structural integration of human neural stem cells grafted into the adult rat spinal cord. Google Patents. 2015.

49. Koh S-H, Park H-H. Neurogenesis in stroke recovery. Translational Stroke Research. 2017; 8(1):3-13.

50. Chen X, Zhou B, Yan T, Wu H, Feng J, Chen H, et al. Peroxynitrite enhances self-renewal, proliferation and neuronal differentiation of neural stem/progenitor cells through activating hif- $1 \hat{\imath} \pm$ and $w n t / \hat{\imath}^{2}$-catenin signaling pathway. Free Radical Biology and Medicine. 2018; 117: $158-67$

51. Darsalia V, Allison SJ, Cusulin C, Monni E, Kuzdas D, Therése K, et al. Cell number and timing of transplantation determine survival of human neural stem cell grafts in stroke-damaged rat brain. Journal of Cerebral Blood Flow \& Metabolism. 2011; 31(1): 235-42.

52. Pittenger MF, Mackay AM, Beck SC, Jaiswal RK, Douglas R, Mosca JD, et al. Multilineage potential of adult human mesenchymal stem cells. Science. 1999; 284(5411): 143-7.

53. Shen Y, Venkat P, Chopp M, Chen J. Mesenchymal stromal cell therapy of stroke. Cellular and Molecular Approaches to Regeneration and Repair. 2018; 217-37.

54. Kurozumi K, Nakamura K, Tamiya T, Kawano Y, Ishii K, Kobune M, et al. Mesenchymal stem cells that produce neurotrophic factors reduce ischemic damage in the rat middle cerebral artery occlusion model. Molecular Therapy. 2005; 11(1): 96-104.

55. Toyoshima A, Yasuhara T, Kameda M, Morimoto J, Takeuchi H, Wang F, et al. Intra-arterial transplantation of allogeneic mesenchymal stem cells mounts neuroprotective effects in a transient ischemic stroke model in rats: analyses of therapeutic time window and its mechanisms. PloS One. 2015; 10(6): e0127302.

56. Kurozumi K, Nakamura K, Tamiya T, Kawano Y, Kobune M, Hirai S, et al. BDNF gene-modified mesenchymal stem cells promote functional recovery and reduce infarct size in the rat middle cerebral artery occlusion model. Molecular Therapy. 2004; 9(2): 189-97.

57. Baraniak PR, McDevitt TC. Stem cell paracrine actions and tissue regeneration. Regenerative Medicine. 2010; 5(1):121-43.

58. Shen LH, Xin H, Li Y, Zhang RL, Cui Y, Zhang L, et al. Endogenous tissue plasminogen activator mediates bone marrow stromal cell-induced neurite remodeling after stroke in mice. Stroke. 2011; 42(2): 459-64.

59. Leu S, Lin Y-C, Yuen C-M, Yen C-H, Kao Y-H, Sun C-K, et al. Adipose-derived mesenchymal stem cells markedly attenuate brain infarct size and improve neurological function in rats. Journal of Translational Medicine. 2010; 8(1): 63

60. Heo JS, Choi Y, Kim H-S, Kim HO. Comparison of molecular profiles of human mesenchymal stem cells derived from bone marrow, umbilical cord blood, placenta and adipose tissue. International Journal of Molecular Medicine. 2016; 37(1): 115-25.

61. Shichinohe H, Ishihara T, Takahashi K, Tanaka Y, Miyamoto M, Yamauchi T, et al. Bone marrow stromal cells rescue ischemic brain by trophic effects and phenotypic change toward neural cells. Neurorehabilitation and Neural Repair. 2015; 29(1): 80-9.

62. Jin K, Mao XO, Sun Y, Xie L, Greenberg DA. Stem cell factor stimulates neurogenesis in vitro and in vivo. The Journal of Clinical Investigation. 2004; 110(3): 311-9.

63. Chen J, Li Y, Wang L, Zhang Z, Lu D, Lu M, et al. Therapeutic benefit of intravenous administration of bone marrow stromal cells after cerebral ischemia in rats. Stroke. 2011; 32(4): 1005-11.

64. Deng S, Zhang S, Sun K, Wang R, Wang J, Lin Y. Fundamental concepts and features of mesenchymal $\mathrm{s}$ tem cells: proliferation, differentiation, migration and immunomodulatory characteristics. Mesenchymal Stem Cells and Craniofacial Regeneration. 2016; 3-32.

65. Scheibe F, Ladhoff J, Huck J, Grohmann M, Blazej K, Oersal A, et al. Immune effects of mesenchymal stromal cells in experimental stroke. Journal of Cerebral Blood Flow \& Metabolism. 2012; 32(8): 1578-88.

66. Doeppner TR, Ewert TAS, TöNGES L, Herz J, Zechariah A, ElAli A, et al. Transduction of neural precursor cells with tat-heat shock protein 70 chaperone: therapeutic potential against ischemic stroke after intras triatal and systemic transplantation. Stem Cells. 2012; 30(6): 1297-310.

67. Jin K, Mao X, Xie L, Galvan V, Lai B, Wang Y, et al. Transplantation of human neural precursor cells in 
Matrigel scaffolding improves outcome from focal cerebral ischemia after delayed postischemic treatment in rats. Journal of Cerebral Blood Flow \& Metabolism. 2010; 30(3): 534-44.

68. Khalil MM, Tremoleda JL, Bayomy TB, Gsell W. Molecular SPECT imaging: an overview. International Journal of Molecular Imaging. 2011; 2011.

69. Hicks A, Jolkkonen J. Challenges and possibilities of intravascular cell therapy in stroke. Acta Neurobiol Exp (Wars). 2009; 69(1): 1-11.
70. Arbab AS, Thiffault C, Navia B, Victor SJ, Hong $\mathrm{K}$, Zhang L, et al. Tracking of In-111-labeled human umbilical tissue-derived cells (hUTC) in a rat model of cerebral ischemia using SPECT imaging. BMC Medical Imaging. 2012; 12(1): 33.

71. Gervois P, Wolfs E, Ratajczak J, Dillen Y, Vangansewinkel T, Hilkens P, et al. Stem cellâ€-based therapies for ischemic stroke: preclinical results and the potential of imagingâ€-assisted evaluation of donor cell fate and mechanisms of brain regeneration. Medicinal Research Reviews. 2016; 36(6): 1080-126. 